\title{
Bioévaluation de la pollution des sédiments de la Seine (région parisienne) par l'emploi d'un bioessai basé sur la croissance à court terme de la micro-algue Selenastrum capricornutum Printz \\ Action of sediments in the River Seine (Paris area) on the short term development of cultures of the micro-alga Selenastrum capricornutum Printz
}

\author{
J. C. Lacaze, A. Chesterikoff et B. Garban
}

Volume 2, numéro 3, 1989

URI : https://id.erudit.org/iderudit/705037ar

DOI : https://doi.org/10.7202/705037ar

Aller au sommaire du numéro

Éditeur(s)

Université du Québec - INRS-Eau, Terre et Environnement (INRS-ETE)

ISSN

0992-7158 (imprimé)

1718-8598 (numérique)

Découvrir la revue

Citer cet article

Lacaze, J. C., Chesterikoff, A. \& Garban, B. (1989). Bioévaluation de la pollution des sédiments de la Seine (région parisienne) par l'emploi d'un bioessai basé sur la croissance à court terme de la micro-algue Selenastrum capricornutum Printz. Revue des sciences de l'eau / Journal of Water Science, 2(3), 405-427. https://doi.org/10.7202/705037ar

\section{Résumé de l'article}

La bioévaluation de l'état de santé des fonds meubles dépend des conditions expérimentales du traitement des échantillons de sédiment conduisant à l'obtention de la phase aqueuse sur laquelle sont effectuées les analyses chimiques et toxicologiques.

$\mathrm{Au}$ cours de cette étude préliminaire nous avons considéré l'action de ces principales conditions ; nous constatons que l'effet inhibiteur d'un sédiment vis-à-vis de la croissance à court terme de la micro-algue Selenastrum capricornutum Printz n'est pas aisément levé, que ce soit par lessivages successifs du sédiment, par filtration plus fine de l'eau extraite à partir de ce dernier ou par autoclavage préalable de ce même sédiment, il peut l'être par contre après biodégradation.

Cette étude expérimentale a permis de comparer entre eux les pouvoirs inhibiteurs des fonds meubles de la Seine (région parisienne).

On note qu'il n'y a pas de corrélation entre les teneurs en métaux lourds souvent importantes des eaux issues des sédiments ( $\mathrm{Pb} 70, \mathrm{Cu} 100, \mathrm{Cr} 150, \mathrm{Cd} 9$, Ni 280, Zn $400 \mu \mathrm{g} . \mathrm{L}^{-1}$ ) et le développement des algues : les polluants métalliques sont masqués par le pouvoir chélateur de ces biotopes riches en substances organiques.

Une conclusion à cette étude préliminaire est que l'analyse chimique des sédiments, utilisée seule, n'a qu'un intérêt limité : les données les plus fiables correspondent à celles fournies par les bioessais. 


\section{Bioévaluation de la pollution des sédiments de la Seine (région parisienne) par l'emploi d'un bioessai basé sur la croissance à court terme de la micro- algue Selenastrum capricornutum Printz}

Action of sediments in the River Seine (Paris area) on the short term development of cultures of the micro-alga Selenastrum capricornutum Printz

J.C. LACAZE (1), A. CHESTERIKOFF (2), B. GARBAN (2)

RéSUMÉ

La bioévaluation de l'état de santé des fonds meubles dépend des conditions expérimentales du traitement des échantillons de sédiment conduisant à l'obtention de la phase aqueuse sur laquelle sont effectuées les analyses chimiques et toxicologiques.

Au cours de cette étude préliminaire nous avons ccnsidéré l'action de ces principales conditions; nous constatons que. l'effet inhibiteur d'un sédiment vis-à-vis de la croissance à court terme de la micro-algue Selenastmum capricomutum Printz n'est pas aisement levé, que ce soit par lessivages successifs du sédiment, par filtration plus fine de l'eau extraite à partir de ce dernier ou par autoclavage préalable de ce même sédiment, il peut l'être par contre après biodégradation.

Cette étude expérimentale a permis de comparer entre eux les pouvoirs inhibiteurs des fonds meubles de la Seine (région parisienne).

On note qu'il n'y a pas de corrélation entre les teneurs en métaux lourds souvent importantes des eaux issues des sédiments ( $\mathrm{Pb} 70, \mathrm{Cu} 100, \mathrm{Cr} 150, \mathrm{Cd} 9, \mathrm{Ni} 280, \mathrm{Zn} 400 \mu \mathrm{g} . \mathrm{L}^{-1}$ ) et le développement des algues : les polluants métalliques

(1) Institut Dcéanographique et Muséum national d'Histoire naturelle, 195, rue Saint-Jacques, 75005 Paris, France.

(2) Institut d'H'drologie et de Climatologie, Université Pierre et Marie Curie, 4, place Jussieu, T. 26, 75252 Paris Cédex 05, France. 
sont masqués par le polivoir chélateur de ces biotopes $r$ iches en substances organiques.

Une conclusion à cette étude préliminaire est que L'analyse chimique des sédiments, utilisée seule, n'a qu'un intérêt limité : les donnèes les plus fiables correspondent à celles fournies par les bioessais.

Mots clés : polluticn des sédiments, bicessais par l'emploi de micicalgues, qualité de l'eau.

SUMMARY

A bioevaluation of the state of health of soft bottoms depends on the experimental conditions in which samples of sediment are treated to obtain the water phase to be subjected to chemical and toxicological analyses.

In the course of this preliminary study we have considered the action of these principal conditions. We have noted that the inhibiting effect of a sediment on the short-term growth of a microalga bienatrum camicomutum is not easy to etiminate, whether by a series of washes of the sediment, by a finer filtration of the water extracted from this sediment or by a previous autoclavage of this sediment.

This study quickly revealed which sediments in the River Seirie (Paris area) inhibited most the test micro-alga Selenastrum capricomutum (chlorophyceae); the cause of these inhibitions. was then sought.

There is no correlation between the often high content of heavy metals in the sediment water ( $\mathrm{Pb} 70, \mathrm{Cu} 100, \mathrm{Cr} 150, \mathrm{Cd} 9$, $\mathrm{Ni} 280, \mathrm{Zn} 400 \mathrm{\mu g} \cdot \mathrm{L}^{-1}$ ) and the development of the algae; the metal pollutants are probabiy masked by the chelating capacity of these biotopes $r i c h$ in organic substances. The experimental conditions under which the sediment samples are treated to obtain the water phase used for the chemical and toxicological analyses are also important.

One conclusion drawn is that a chemical analysis alone of the sediments is of limited interest. The most reliable data from the ecological point of view are those provided by the bio-assays.

Key-words : sediments pollution, microalgae bioassays, water quality.

INTRODUCTION

Les polluants dêversés dans les eaux se retrouvent, pour une grande part, dans les sédiments, gënéralement après une fixation plus ou moins 
temporaire par les organismes planctoniques. Les fonds meubles se comportent comme des indicateurs de pollution.

L'analyse chimique des polluants dans les sédiments constitue le moyen d'investigation habituel. Toutefois, elle ne rend pas toujours compte de l'effet réel de la pollution car elle n'est jamais exhaustive : tous les polluants ne peuvent être pris en compte. En outre, l'analyse chimique mesure la "pollution brute" non la "pollution nette" c'est-à-dire celle que nous définirons ici comme agissant réellement sux les organismes : le problème se pose aussi en cas d'eutrophisation, l'azote, et plus particulièrement le phosphore analysés dans les sédiments ne sont pas forcément biodisponibles.

L'emploi de bioessais est donc une nécessité comme plusieurs auteurs l'ont souligné (HANNAN et PATOUILLET, 1976, 1979; LACAZE, 1987 ; LACAZE et PAQUET, 1989).

La bioévaluation de l'état de santé des sédiments est réalisée ici par la mesure de la crcissance à court terme ( 96 heures) de la microalgue Selenastrum capricomution printz (Chlorophyceae), algue de référence pour l'êtude des eaux douces polluées.

Dans presque tous les cas il est nécessaire d'extraire les eaux associées au sédiment ce qui peut être réalisé par centrifugation juste après les prélèvements (LACAZE, 1987) : cette opération n'était malheureusement pas réalisable ici, à proximité đes lieux de récolte.

Il est également possible de brasser dans des conditions expérimentales parfaitement définies des quantités aliquotes d'eau et de sédiment. C'est cette méthodologie que nous employons dans ce travail exploratoire en fixant certains paramètres tels que l'intensité et la durée du brassage, la proportion eau/sédiment. et en étudiant l'influence d'autres : évaluation de la toxicité du sédiment en foncticn de lessivages successifs, influence du degré de filtraticn, de l'autoclavage ou de la biodégradation fréalables.

En fonction des résultats obtenus, un protocole d'extraction provisoire est déterminé et appliqué à l'étude comparée des inhibitions et fertilisations potentielles de sédiments prélevés sur le fond de la Seine.

\section{1 - Matériel et méthodes}

\section{1-1 Choix des stations}

Le test algue est utilisé sur du sédiment provenant de 9 localités de la région parisienne. plusieurs de ces stations sont portées sur. la figure 1. D'autres stations, situées dans la région de Montereau, donc beaucoup plus en amont, ne figurent pas sur cette carte. Parmi ces dernières on distingue :

Dans la ville de Montereau :

- Montereau - Seine (bras de la Seine).

- Montereau - Yonne (bras de I'Yonne). 
A $15 \mathrm{~km}$ en amont de cette ville, à l'entrée d'une sablière :

- Balloy 1 (dominance sable) ;

- Balloy 2 (forte dominance vase).

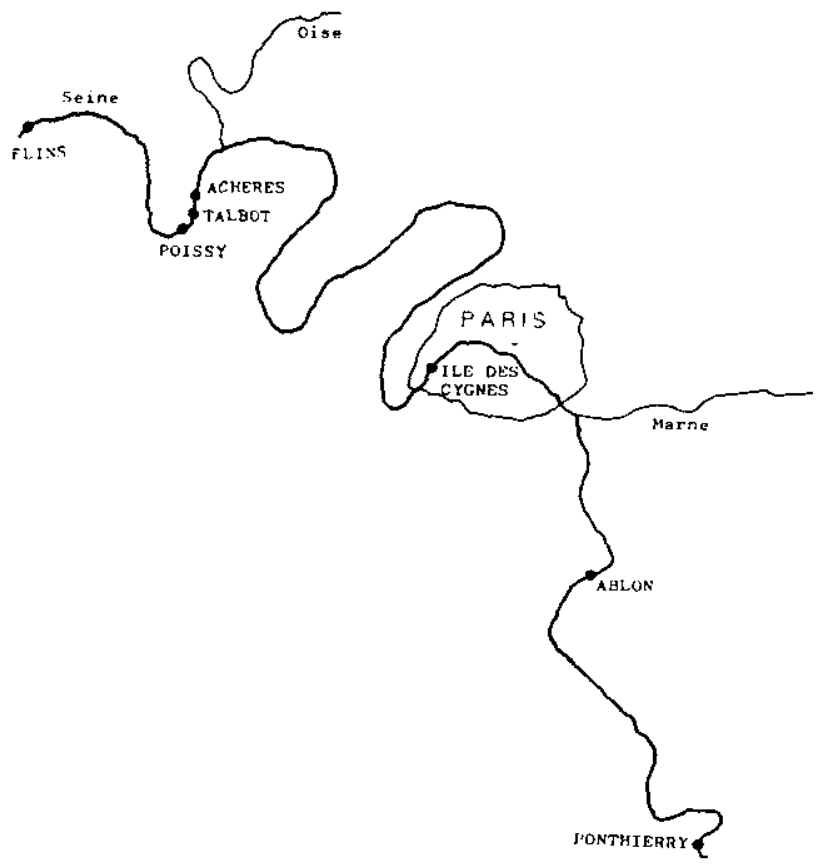

Figure 1.- Carte de la zone d'étude et localisatior des sites de prélèvements.

Figure 1. - Map of the study area and localization of sompling sites.

Par ailleurs nous avons utilisé comme référence un échantillon de sol (terre de jardin, cf. tableau 3).

Plusieurs prélèvements sont réalisếs poux les localités d'Achères (Station d'épuration), de Poissy (Usines Talbot), et de Flins (Usine Renault). Pour chacune d'entre elles la numérotation des stations croit d'amont en aval, le prélèvement numéro 1 étant effectué en amont des rejets d'eaux usées.

\section{1-2 Choix de l'algue}

L'algue verte Selenastmum capmicomutum Printz (Chlorophyceae) est reterue pour sa représentativité des milieux oligotrophes et eutrophes, la maintenance aisée des cultures avec de faibles variations morphologiques, ainsi que la facilité des dénombrements (absence de coenobes). Nous utilisons ici la scuche réfërence NIVA CHL 1 (Norwegien Institute for water Research). Cette algue est très employée pour les tests de fertilité en eauy douces polluées ; plus de 200 publicaticns concernent 
cette espèce qui constitue de ce fait une "référence" (BONIN et al., 1986).

\section{1-3 Réalisation du test}

Deux paramètres, taux de croissarce et biomasse maximale sont généralement utilisés lors de l'emploi d'algues en cultures non renouvelées (batch cultures), l'un plus apte à mesurer les inhibitions dues aux pollutions et lié à la phase exponentielle qui se présente au début du développement des cultures, l'autre indiquant le potentiel d'eutrophisation et obtenu pour des durées plus grandes (MAESTRINI et al., 1984, Passim).

Le test à court terme ( 96 heures) utilisé dans le cadre de ce travail réalisé sur de nombreux échantillons, intègre donc la phase initiale du développement des cultures. La phase de plateau correspondant à la biomasse maximale et permettant de déterminer le potentiel maximal de croissance (AGP : algal growth potential) n'est pas encore atteint. Lors d'un travail complémentaire, que nous avons réalisé conjointement à celui-ci, cette 2 ème phase est mise plus particulièremert en évidence sur les mêmes sédiments mais avec un protocole d'étude différent ; l'expérimentation est alors prolongée au-delà de 10 jours (IACAZE et al., 1989). Ici, l'action inhibitrice d'un extrait aqueux obtenu à partir d'un sédiment s'exercexa sur le taux de croissance et la durée de la phase de latence (BLANKLEY, 1973).

Ce test consiste à mesurer la capacité d'une eau, extraite d'un sédiment (cf. protocole d'extraction), à entretenix ou limiter la prolifération de 1'algue verte Selenastmum capricornutum. On évalue le développement de l'algue dans l'extrait ou dans ses dilutions après une période de 96 heures. La biomasse, liée au développement de I'algue, est déterminée par dosage de la chlorophylle a (SCOR-UNESCO, 1986).

Lorsqu'on considère la surveillance du milieu aquatique, laquelle constitue aujourd'hui une priorité absolue, on doit comprendre, ce qui $n$ 'est pas évident pour beaucoup de chercheurs, que le choix des tests ne repose pas uniquement sur des concepts strictement scientifiques, ces derniers étant d'ailleurs paifaitement répertoriés dans le domaine des micro-algues (MAESTRINI et al., 1984) mais aussi sur d'autres paramètres tels que la rapidité, le coût peu élevé, etc. (LACAZE, 1987). C'est aussi cet aspect qui est pris en compte pour l'élaboration des normes nationales et internationale (AFNOR, 1980).

Ainsi, certaines méthodes d'évaluation plus fines ou plus "scientifiques" mais nécessitant un matêriel coûteux, une technologie sophistiquée ou l'implication de techniques très spécialisées ne présentent parfois que peu d'intérêt pratique. Des bioessais plus simples peuvent - dans l'état présent des recherches - permettre néanmoins de détecter les altérations de la quajité des milieux et guider les travaux futurs (BLANDIN, 1986) ; c'est cet objectif que nous avons tenté d'atteindre avec ce travail.

Les expéximentations sont conduites dans des flacons de verxe (col vissé) de $100 \mathrm{ml}$. Ces derniers contiennent des quantitếs croissantes d'eaux à tester (extrait), à savoir, 0 (témoins), 5, 10, 15, $20 \mathrm{ml}$; ces volumes sont, le cas échéant, portés à $20 \mathrm{ml}$ par addition du milieu de culture comprenant tous les éléments à l'exception des macro et micro-nutriments (tableau 1) qui sont introduits ensuite afin de recons- 
tituer le milieu de culture habituel (PAAP; Provisional algal Assay Procedure ; EPA, 1978).

Tableau 1.- Composition du milieu de culture PAAP. Concentrations finales er: macro et micro-éléments.

Table 1.- Composition of thi PAAP culture medium. Final concertrations of macro- and microelements.

CONCENTRATION FINALE EN MACRO-ELEMENTS

\begin{tabular}{|c|c|c|c|c|}
\hline & Composếs & $\mathrm{mg} / \mathrm{l}$ & Elément & $\mathrm{mg} / 1$ \\
\hline $\mathrm{NaNO}_{3}$. & $\ldots \ldots \ldots \ldots$ & 25,500 & $N$ & 4,200 \\
\hline $\mathrm{MgCl}_{2} \cdot 6$ & $6 \mathrm{H}_{2}{ }_{2} \mathrm{O} \ldots \ldots \ldots$ & 12,164 & $\mathrm{Mg}$ & 2,904 \\
\hline $\mathrm{CaCl}_{2} \cdot 2$ & $2 \mathrm{H}_{2} \mathrm{O} \ldots \ldots \ldots$ & 4,410 & $\mathrm{Ca}$ & 1,202 \\
\hline $\mathrm{MgSO}_{4} \cdot 7$ & $7 \mathrm{H}_{2} \mathrm{O} \ldots \ldots \ldots$ & 14,700 & $S$ & 1,911 \\
\hline $\mathrm{K}_{2} \mathrm{HPO}_{4}$ & $\ldots \ldots \ldots \ldots$ & 1,044 & $\mathrm{P}$ & 0,186 \\
\hline \multirow[t]{3}{*}{$\mathrm{NaHiCO}_{3}$} & $\ldots \ldots \ldots \ldots$ & 15,000 & $\mathrm{Na}$ & 11,001 \\
\hline & & & K & 0,469 \\
\hline & & & $\mathrm{C}$ & 2,143 \\
\hline
\end{tabular}

CONCENTRATION FINAIE EN MICRO-ELEMENTS

\begin{tabular}{|c|c|c|c|}
\hline Composés & $\mathrm{mg} / 1$ & Elément & $\mathrm{mg} / \mathrm{l}$ \\
\hline $\mathrm{H}_{3} \mathrm{BO}_{3} \ldots \ldots \ldots \ldots$ & 185,520 & $\mathrm{~B}$ & 32,460 \\
\hline $\mathrm{MnCl}_{2}-4 \mathrm{H}_{2} \mathrm{O} \quad \ldots \ldots \ldots$ & 415,610 & $\mathrm{Mn}$ & $1 \pm 5,374$ \\
\hline $\mathrm{ZnCl}_{2} \ldots \ldots \ldots \ldots$ & 3,271 & $\mathrm{Zn}$ & 1,570 \\
\hline $\mathrm{CoCl}_{2} \cdot 6 \mathrm{H}_{2} \mathrm{O} \quad \ldots \ldots \ldots$ & 1,428 & $\mathrm{Co}$ & 0,354 \\
\hline $\mathrm{CuCl}_{2} \cdot 2 \mathrm{H}_{2} \mathrm{O} \ldots \ldots \ldots$ & 0,012 & $\mathrm{Cu}$ & 0,004 \\
\hline $\mathrm{Na}_{2} \mathrm{MOO}_{4} \cdot 2 \mathrm{H}_{2} \mathrm{O} \ldots \ldots$ & 7,260 & Mo & 2,878 \\
\hline $\mathrm{FeCl}_{3} \cdot 6 \mathrm{H}_{2} \mathrm{O} \ldots \ldots \ldots$ & 160,000 & $\mathrm{Fe}$ & 33,051 \\
\hline $\mathrm{Na}_{2}$ EDTA. $2 \mathrm{H}_{2} \mathrm{O} \ldots \ldots$ & 300,000 & - & - \\
\hline
\end{tabular}

Le milieu ccimplet est élaboré à pertir de 6 solutions mères de macroéléments et d'une solution mère de micro-éléments contenant 1'EDTA. Les dilutions sont effectuées à l'aide d'eau biơistillée stérile. Les algues se développent donc, dans tous les cas, avec des concentrations en nutriments au moins égales à celles du milieu de culture habituel ; par conséquent, un développement moindre pār rapport aux cultures témoins ne peut être attribué à des carences en $\mathrm{N}$ et $\mathrm{P}$ : il indique une inhibition dont nous chercherons ici les causes.

Trois flacons sont utilisés par concentration. Les rếsultats présentés sur les figures sont la moyenne des valeurs obtenues.

On inocule ensuite $1 \mathrm{ml}$ d'une culture de Selenastmum capricomutum se développant également. en milieu PAAP.

Les flacons sont disposés sous une rampe constituée de tubes fluorescents Gro-lux. Photopériode $12 / 12$. Energie lumineuse : $1,8 \mathrm{~mW} / \mathrm{cm}^{2}$. Température $20^{\circ} \mathrm{C} \pm 1{ }^{\circ} \mathrm{C}$. Iors de 7 essais préliminaires (cf. cj.-dessous; intervalle de confiance $p<0,05)$ pour tester la croissance de 1 'algue dans nos conditicns expérimentales nous obtenons des taux de croissance 
(nombre de divisions par joux) de 1,1, proches de ceux relevés lors đ'expériences complémentaires (LACAZE et al., 1989) :

\begin{tabular}{lcc}
\hline & Données initiales & Données après 96 heures \\
\hline $\begin{array}{l}\text { Chloro a } \\
\mu g \cdot L^{-1}\end{array}$ & $33 \pm 6$ & $549 \pm 32$ \\
$\begin{array}{l}\text { Nombre de } \\
\text { cellules }\end{array}$ & $97857 \pm 9477$ & $2,15.10^{6} \pm 0,24.10^{6}$ \\
\hline
\end{tabular}

\section{1-4 Protocole d'extraction des eaux à étudier}

Ce protocole est très proche de ceux précédemment utilisés par HANNAN et PATOUILLET (1979) et LACAZE (1987).

Les échantillons de sédiment sont congelês imméđiatement après les prélèvements. Ceux-ci sont réalisés pār carottages à pârtir d'un des bateau du service de la navigation de la Seine. Seuls les 3 premiers centimètres sont recueillis, car seule la partie superficielle est apte à être remaniée sous l'effet de l'hydrodynamisme naturel ou provoqué par le passage frëquent des bateaux à hélice et donc susceptible d'avoir un impact sur le milieu sus-jacent. Dans un cas (essais de biodégradation) on évite la congélation et on procède directement à l'essai.

Les sédiments sont dêcongelés juste avant la réalisation des tests. on brasse alors une part de sédiment dans 3 parts de milieu PAAP (exempt de macro et micro-nutriments) c'est-ä-dire sans Azote et Phosphore ainsi cue sans la solution de micrc-éléments (tableau 1), puis on réalise une agitation mécar:ique durant $30 \mathrm{~min}$. (appareil à agitation par va-et-vient). Ces propoxtions sont choisies pour des raisons pratiques. Elles conduisent à des concentrations suffisantes en nutriments et altéragènes poux pouvoir réaliser les analyses chimiques et toxicologiques dans de bonnes conditions.

Après une décantation de 3 heures on centrifuge le surnageant (5 $000 \mathrm{t} / \mathrm{min} ., 5 \mathrm{~min}$ ) puis on filtre la phase supérieure sur papier Whatman GF/C. Dans quelques cas on procède à une deuxième filtration sur millipore GS, porosité $0,22 \mu \mathrm{m}$.

\section{1-5 Analyses chimiques}

Une paxtie aliquote des eaux à tester est analysée chimiquement pour les substances sujvantes :

- sels nutritifs. Méthodes spectrophotcmétriques (Normes AFNOR, T 90013, T 90015, T 90023) ;

- azote total (méthode INRA - SHL, Thonon) et azote organique (différence entre l'azote total et la somme des formes minérales de 1 'azote) :

- métaux lourds par spectrophotométrie d'absorption atomique. 
Au cours de cette étude prêliminaire nous considérerons l'action de plusievrs paramètres importants du traiterient des sédiments notamment l'influence de lessivages successifs, la filtration plus fine des extraits, et l'autoclavage préalable du sêdiment; puis, en s'appuyant sur les résultats obtenus nous déterminerons un protocole provisoire d'extraction afin de comparer ertre elles les caractéristiques inhibitrices et fertilisantes de 14 échantillons de sédiments provenant du it de la Seine.

\section{2-1 Influence des conditions de traitement des sëdiments}

Le traitement des échantillons de sédiment qui conduit à l'obtention de la phase aqueuse sur laquelle sor.t effectuées les analyses chimiques et toxicologiques est une opération capitale car il conditionne en grande partie ces analyses. Déjà, dans le cas des essais portant sur les eaux, cette question est l'objet d'importantes divergences entre les auteurs (CROUZET et VIILESSOT, 1987). En premier lieu la question de la congélation ou de la décongélation du sédiment. se pose car il n'est généralement pas possible d'analyser immédiatement les sédiments souvent prélevés en grand nombre ; ce type de conservation dont nous n'étudierons pas ici I'incidence est susceptible de modifier le résultat des essais.

Toutefois le vrai problème est de savoir comment, à partir d'un sêdiment, obtenir une inage rẻaliste, au plan écologique, de son caractère inhibiteux ou fertilisant. L'état physico-chimique et par conséquent toxicologique de la phase aqueuse extraite du sédiment dépendra de nombreux paramètres, notamment : intensité et durée du brassage, proportions eau/sédiment. Il dépendra également du traitement subi par l'extrait, le plus souvent. pour assurex sa stérilisation (filtration, autoclavage).

Dans le cas d'un sédiment. "frais" n'ayant subi aucun traitement il est également possible de soumettre le mélange eau-sédiment à une biodégrzdation en réacteur et de réaliser des analyses chimiques et toxicologiques à intervalles réguliers. Ce protocole a été utilisé ici pour la localité de Balloy 2 dans le cas d'un échantillon de vase très riche en matières organiques.

Quels sont les principaux paramètres intervenant sur les effets biologiques?

\section{2-1-1 Influence de lessivages successifs}

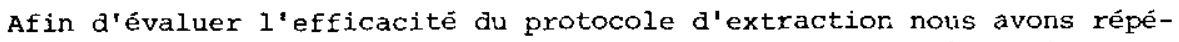
té les différentes phases de l'operation de lessivage pour 3 stations (Montereau-Seine, Montereau-Yonne, Poissy).

Lorsque on réalise un deuxième lessivage, l'analyse tcxicologique (fig. 2) donne des résultats identiques dans tous les cas. Le tableau 2 nous indique que les analyses chimiques relatives aux nutriments et concernant les eaux issues du premier et du deuxième lessivage sont différentes : le deuxième extrait étant un peu moins riche. Par contre, les concentrations en métaux ne présentent pas d'évoluticn caractéristique ; elles augmentent mēme dans 2 cas sur 3. 


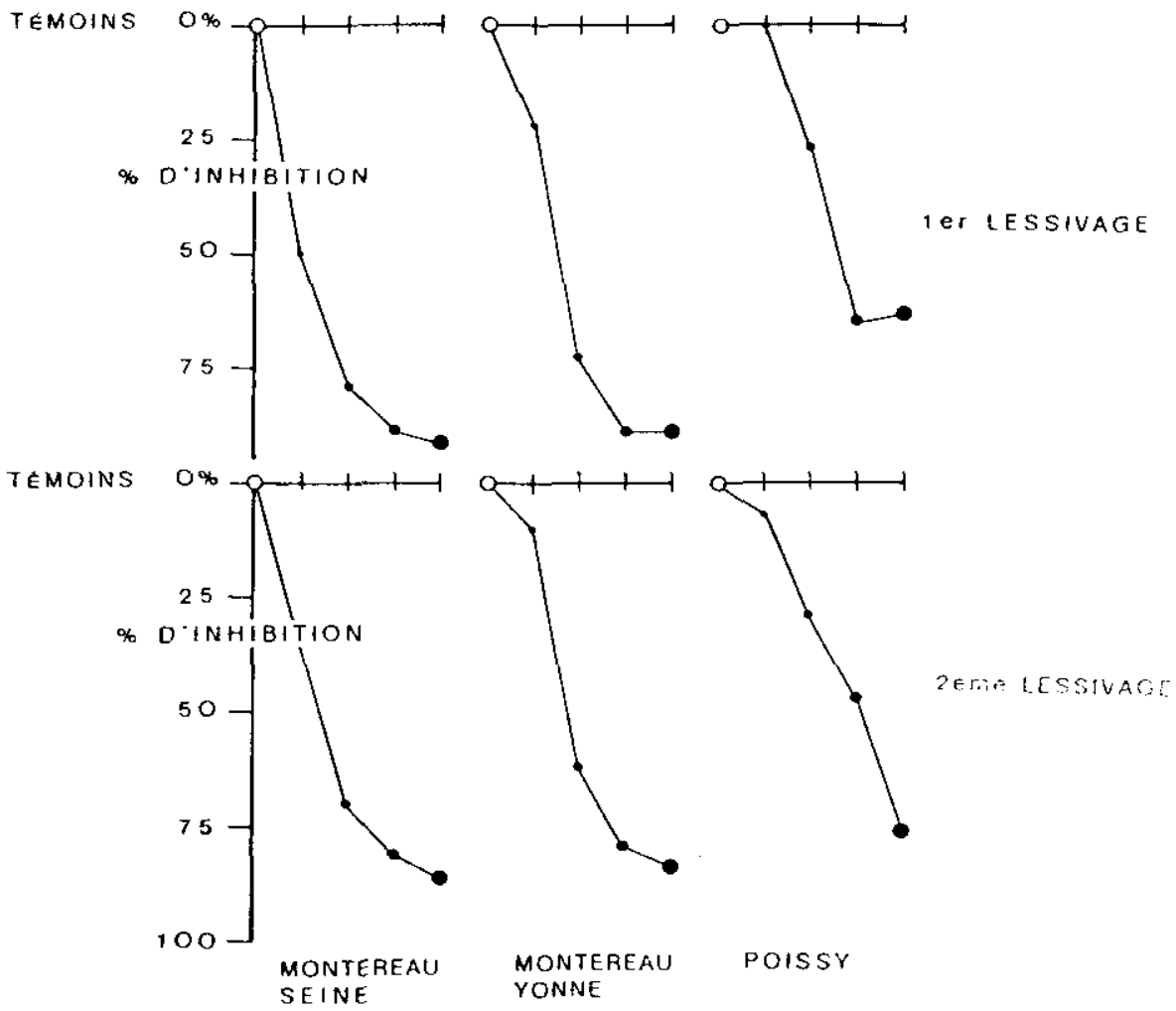

Figure 2.- Influence d'extractions aqueuses successives sur le degré de multiplication de Selenastrum capricornutum.

Figure 2.- Influence of successive water extracts on the rate of multiplication of Selenastrum capricornutum.

Tableau 2. - Nutriments (mg. $\mathrm{L}^{-1}$ ) et métaux lourds ( $\mu \mathrm{g} \cdot \mathrm{L}^{-1}$ ) des extraits aqueux après lessivages successifs :

(1) : premier lessivage. (2) : deuxième lessivage.

Table 2.- Nutrients (mg. $L^{-1}$ ) and heavy metals ( $\mu g . L^{-1}$ ) in water extracts after successive washings :

(1) : first washing; (2) second washing.

\begin{tabular}{lllllllll}
\hline & & $\mathrm{N}^{2} \mathrm{NH}_{4}$ & $\mathrm{P}^{2} \mathrm{PO}_{4}$ & $\mathrm{~Pb}$ & $\mathrm{Cd}$ & $\mathrm{Cu}$ & $\mathrm{Cr}$ & $\mathrm{pH}$ \\
\hline \multirow{2}{*}{ Montereau Seine } & $(1)$ & 50 & 0,25 & 33 & 1 & 63 & 19 & 7,16 \\
& $(2)$ & 34,4 & 0,14 & 24 & 1 & 13 & 4 & - \\
\multirow{2}{*}{ Montereau Yonne } & $(1)$ & 22 & 0,08 & 13 & 1 & 8 & 7 & 7,27 \\
\multirow{5}{*}{ Poissy } & $(2)$ & 16,4 & 0,07 & 16 & 1 & 9 & 18 & - \\
& $(1)$ & 70 & 5,9 & 32 & 1 & 31 & 17 & 7,60 \\
& $(2)$ & 46 & 4,2 & 60 & 4 & 82 & 56 & - \\
\hline
\end{tabular}


Quoi qu'il en soit ces données nous indiquent que deux lavages successifs seulement n'épuisent pas les sédjments en substances inhibitrices.

2-1-2 Influence d'une filtration plus fine des extraits aqueux

Au cours de ce travail nous avons pratiqué (cf. protocole d'extraction) en routine, une filtration à 0,45 un envixon (Whatman GF/C) . celle-ci, généralement réalisée dans le cas des essais portant sur les eaux, élimine la matière organique du plancton préexistant.

Dans 4 cas une filtration plus poussée (millipore GS, poxosité $0.22 \mu \mathrm{m}$ ) est réalisée ; on constate alors par rapport aux données habituelles obtenues par filtration sur $0,45 \mathrm{jm}$, une augmentation moyenne de l'ordre de 15 \& de la biomasse chlorophylienne pour toutes les concentrations (fig. 3), ce qui signifie que, si la filtration sur $0,22 \mu \mathrm{m}$ augmente quelçue peu le développenent des algues, elile n'élimine, pas, pour autant, les composés responsables de l'inhibition.

Une hypothèse doit être prise en compte. On sait que le phosphore est. adsorbé sur le mātériel particulaire et alors peu biodisponible, cette fixation dépendant de la nature des sédiments et du pH (CROUzET et VILLESSOT, 1987). C'est ce que nous observors ici : l'analyse chimique réalisée dans un cas (BALLOY 1, tableau 3) indique une baisse de la concentration en nutriments et une légère augmentation du $\mathrm{pH}$, ce qui laisserait supposer que les particules de taille située entre 0,45 et $0.22 \mu \mathrm{m}$ absorbent une partie des nutriments. Il est probable que ces particules absorbent également des inhibiteurs : la croissance plus importante des algues après une filtration poussée tend à le montrer.

2-1-3 Influence de l'autoclave préalable des échantillons de sédiment

La stérilisation par autoclavage minéralise les cellules mais cette technique brutale cause un dégazage susceptible de précipiter des quantités importantes de certains composés tels que le phosphore qui devient indisponible biologiquement. Nous avons donc étudié lors d'une nouvelle série d'expériences portant sur 7 stations choisies selon un gràdient de polluticn, 1'influence de 1'autoclavage des échantilions de sédiment sur la toxicité (fig. 4).

Dans le cas des sédiments conduisant à une eutrophisation pour toutes les dilutions (Sol, Balloy, Ponthierry) on note, que l'autoclavage augmente fortement celle-ci.

Lorsque, par contre, cette eutxophisation est limitée ou nulle (Ablon, Achères, Poissy) l'autoclavage est sans effet, voire freine le développement des cultures.

Au plan de l'analyse chimique réalisẻe pour 4 des stations (tableau 3), on note que l'autoclavage augmente la concentration en azote organique ce qui peut favoriser 1'eutrophisation dans certains cas ou la limiter dans d'autres selon la nature des composés organiques et leur degré de minéralisatior.

2-1-4 Influence de la biodégradation préalable d'un sédiment. sur ses potentialités inhibitrices ou fertilisantes

Le sédiment étudié (Balloy 2) est prélevé à la fin de l'automne ; il est alors très riche en microalgues en cours de décomposition. cette station est dépourvue de toute pollution d'origine humaine. 


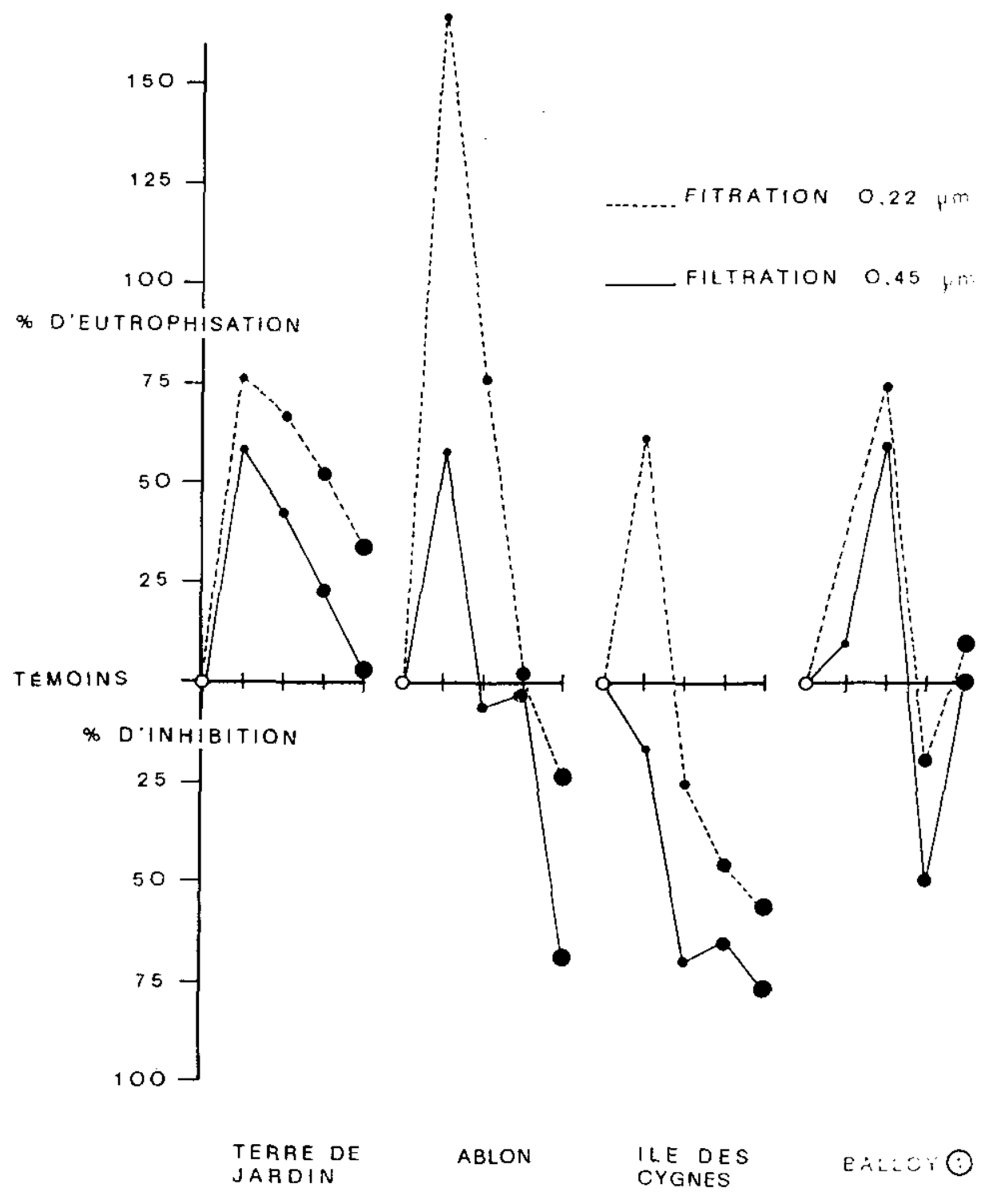

Figure 3. - Influence d'une filtration plus fine $(0,22 \mu \mathrm{m})$ des extraits acqueux sur le degré de multiplication de Selenastrum capricornutum.

Figure 3.- Influence of a finer filtration $(0.22 \mathrm{\mu m})$ of water extracts on the rate of multiplication of Selenastrum capricornutur. 
Tableau 3.- Influence de l'autoclavage des échantillons de sédiments sur la composition de leurs extraits en nutriments (mg. $\mathrm{L}^{-1}$ ) et en métaux lourds $\left(\mu g . I^{-1}\right)$.

Table 3.- Effect of the autoclavage of the sediment samples on the nutrient $\left(\mathrm{mg} / \mathrm{L}^{-1}\right)$ and heavy metal $\left(\mathrm{Hg} / \mathrm{L}^{-1}\right)$ composition.

\begin{tabular}{|c|c|c|c|c|c|c|c|c|c|c|c|c|}
\hline & & $\mathrm{N} . \mathrm{NH}_{4}$ & $\mathrm{~N} . \mathrm{NO}_{3}$ & N.ORG. & $\mathrm{P} \mathrm{PO}_{4}$ & $\mathrm{pb}$ & $\mathrm{Cu}$ & $\mathrm{Cr}$ & $\mathrm{Cd}$ & $\mathrm{Ni}$ & $\mathrm{Zn}$ & $\mathrm{pH}$ \\
\hline TERRE DE JARDIN & A & 1,1 & 1,4 & 15 & 1,1 & 170 & 60 & 30 & 1 & 100 & 80 & - \\
\hline \multirow[t]{3}{*}{ BALLOY 1} & NA & 0,85 & 0,3 & 8 & 0,21 & 15 & 60 & 4 & 1 & 40 & 100 & 8,06 \\
\hline & $+0,22$ & 0,7 & 0,21 & 8 & 0,19 & 5 & 80 & 4 & 1 & 80 & 80 & 8,25 \\
\hline & A & 0,43 & 0,16 & 13,6 & 0,09 & 15 & 40 & 6 & 1 & 100 & 80 & 8,23 \\
\hline \multirow[t]{2}{*}{ ACHERES 1} & NA & 28 & 0.14 & 5 & 1,35 & 56 & 60 & 153 & 9 & 120 & 300 & 7,74 \\
\hline & $A$ & 20 & 0,2 & 25 & 1,75 & 50 & 12 & . 30 & - & 80 & 200 & 7,56 \\
\hline \multirow[t]{2}{*}{ ACHERES 2} & NA & 95 & 0,28 & 0 & 4,32 & 13 & 20 & 42 & 2 & 280 & 300 & 7,47 \\
\hline & A & 79 & 0,2 & 53 & 3,8 & 4 & 10 & 42 & 4 & 120 & 400 & 7,41 \\
\hline \multirow[t]{2}{*}{ POISSY } & NA & 50 & 0,3 & - & 2,4 & & & & & & & 7,60 \\
\hline & $A$ & 40 & 0,23 & 22 & 2,4 & 131 & 100 & 144 & 2 & 68 & 400 & 7,95 \\
\hline
\end{tabular}

$\hat{A}$ : auticlavé;

A : autoclaved ;

N.A. : non autoclavé :

N.A. : non autoclaved ;

$+0,22$ : filtration complémentaire sur $0,22 \mu \mathrm{m}$.

+0.22 : additional filtration on $0.22 \mathrm{um}$ 

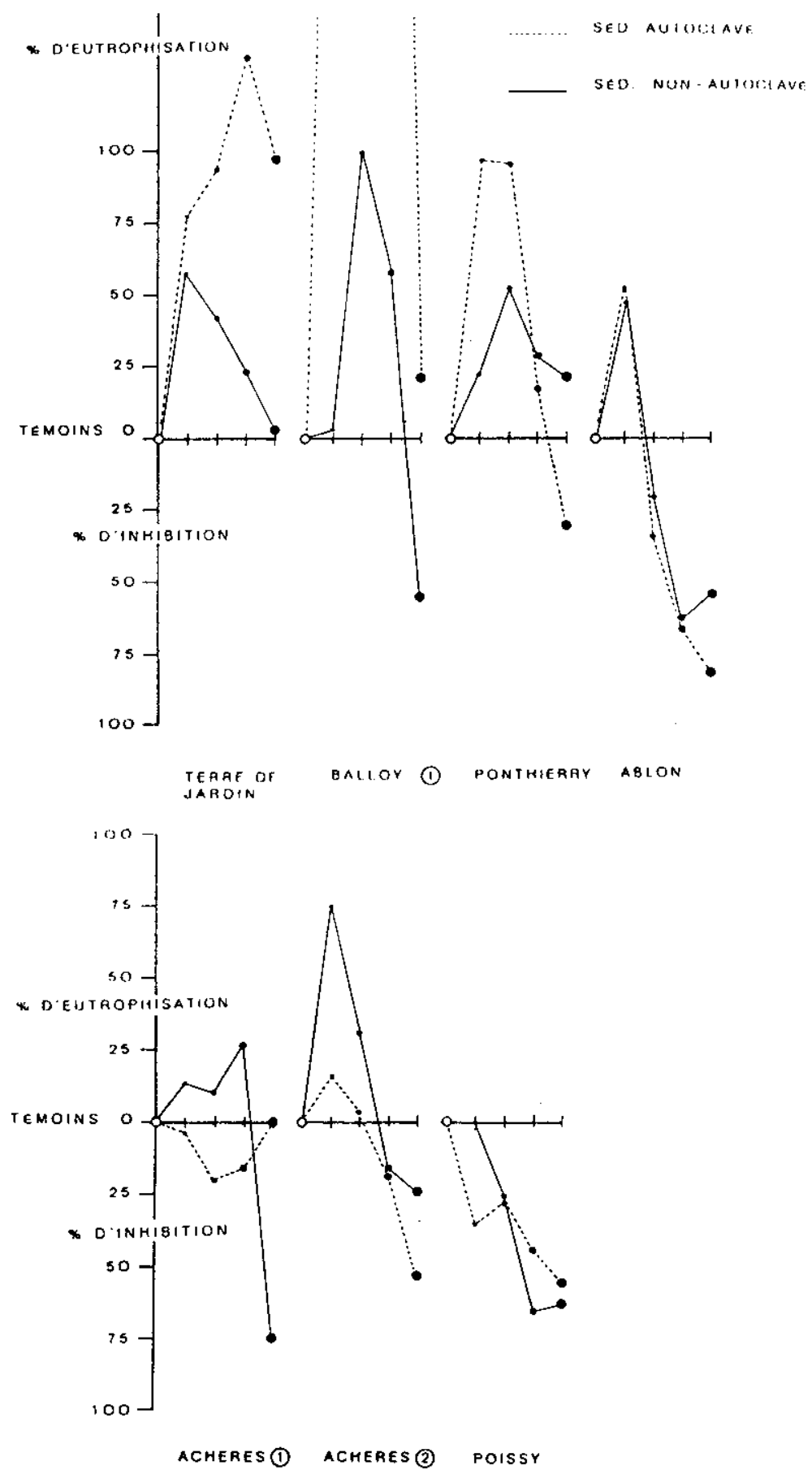

Figure 4.- Influence de l'autoclavage préalable des sédiments sur le degré de multiplication de Selenastrum capricornutum.

Figure 4.- Influence of the prior autcclavage of sediments on the rate of multiplication of selenastrum capricornutum. 
Lors de cette étude, on évite la congélation et on procède directement à l'essaj. avec une micrcflore intacte. Cette pratique appelée méthode microcosmique (IACAZE, 1973, 1976) constitue une des voies que ce travail prêliminaire nous permettra de privilégier ultérieurement.

Le réacteux qui contient le mélange sédiment/eau (proportion 1/3) compose donc un microécosystème expérimental qui va évcluer durant les 10 jours de la période expérimentale. Un brassage de $30 \mathrm{~min}$. par agitation mëcanique est réalisé initialement et chaque jour. Des extraits sont prélevés après 3 heures, 2 et 10 jours pour effectuer les analyses chimiques (tableau 4) et toxicologiques (fig. 5).

Tableau 4.- Concentration en nutriments (mg. $\mathrm{L}^{-1}$ ) et métaux lourds ( $\mathrm{Hg} . \mathrm{L}^{\mathrm{l}}$ ) des extraits aqueux du sédiment de la station Balloy 2 en fonction de la durée de bi.odégradation en milieu rédiuit et oxydé.

Table s.- Hutrient $\left(\mathrm{mg}^{-L^{-I}}\right)$ and heavy metal $\left(\mathrm{g} / L^{-1}\right)$ concentration in water extracts from sediment at station ballos: as a function of the duration of biciegradation in a reduced and oxidate: medium.

\begin{tabular}{|c|c|c|c|c|c|c|c|c|c|c|c|c|}
\hline & & N.NHE. & $\mathrm{N} \cdot \mathrm{NO}_{3}$ & N.ORG. & $\mathrm{P} . \mathrm{PO}_{4}$ & $\mathrm{~Pb}$ & $\mathrm{Cu}$ & $\mathrm{Cr}$ & $c d$ & $\mathrm{Ni}$ & $\mathrm{Zn}$ & $\mathrm{pH}$ \\
\hline \multirow[t]{2}{*}{2 heures } & rêduit & 9,3 & 0,04 & 32 & 0,44 & 8 & 33 & 4 & 1 & 170 & 300 & 7,52 \\
\hline & oxydé & 6.9 & 0.09 & 19 & 0,13 & 18 & 80 & 15 & 1 & 160 & 200 & 7,77 \\
\hline \multirow[t]{2}{*}{2 jours } & réduit & 0,3 & 0,07 & - & - & 19 & 10 & 4 & 4 & 100 & 50 & 7,70 \\
\hline & oxydé & 0,1 & 0.16 & - & - & 9 & 13 & 6 & 18 & 120 & 50 & 7,86 \\
\hline \multirow[t]{2}{*}{10 jours } & rédiait & 2 & 0,2 & 3,6 & - & 4 & 2 & 1 & 1 & 140 & 50 & 7,35 \\
\hline & oxydé & 0,11 & 0.09 & 0,9 & - & 4 & 7 & 2 & 1 & 160 & 50 & 7,86 \\
\hline
\end{tabular}

Pour un élément : $1 \mathrm{~g}=$ ( $1 /$ masse atomique) mol;

pour un composé molécuiaire ou ionique : $1 \mathrm{~g}=(1 / \mathrm{masse}$ molfculaire ou ionique) mol.

For one element : $1 \tilde{s}=$ (1/atomic mess $)$ mol ;

For a molecular or ionic component : $1 \mathrm{~g}=(1 / \mathrm{molecular}$ or ionic mass $)$ mol.

On observe trois phases :

1 - L'eau à étudier après 3 heures de contact avec le sédiment en condition d'agitation par va-et-vient présente une forte inhibition qui peut être partiellement levée lorsque le sédiment est autoclavé préalablement (fig. 5). Cette constatation semble contradictoire avec les exemples cités plus haut ; toutefois nous noterons que le sédiment est ici exempt de toute pollution d'origine industrielle ou urbaine.

2 - Une phase intermédiaire après 2 jours d'incubation du sédiment et de l'eau indique un début d'eutrophisation, et une diminution de l'inhibition.

3 - Une phase finale obtenue après 10 jours d'incubation; une forte eutrophisation est alors apparente. 


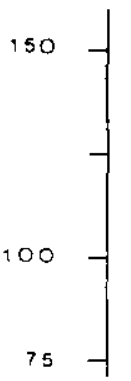

* DEUTROPHISATION
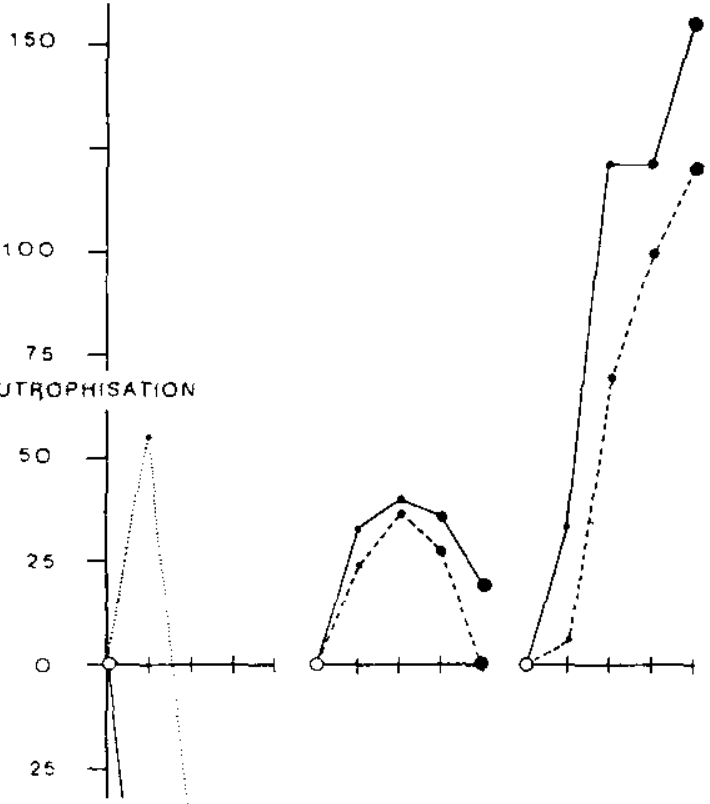

क D.NHIBITION

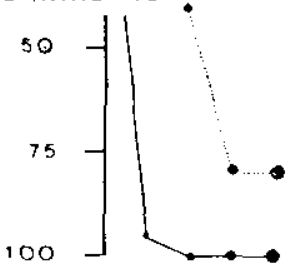

3 MEUAES

10 jours

Figure 5.- Multiplication de Selenastrum capricornutum en fonction đu degré de bjodégradation d'un sédiment (Balloy 2). Influence de I'oxygénation.

Figlire 5.- Multiplication of Selenastrum capricornutum as a function of the degree of biodegradation of a sediment (Balloy 2). Influence of oxygenation.

On note donc, en fonction du temps et de la biodégradation de la matière orgarique, la levée de I'inhibition, principalement pour les concentrations les plus fortes ; il y a après 10 jours proportionnalité entre l'effet eutrophisart et les concentrations (tableau 4). Après 10 jours de biodégradation en milieu oxydé, la concentration en $\mathrm{NH}_{\overline{4}}$ est passée de $493 \mu \mathrm{M}$ à $8 \mu \mathrm{M}$ et celle de l'azote organique de $1357 \mu \mathrm{M}$ à $64 \mu \mathrm{M}$, alors que la concentration de l'ion nitrate reste constante $(6,4 \mathrm{\mu M})$. La question se pose de savcir sous quelle(s) forme (s) les $1778 \mu \mathrm{M}$ ont disparu; ou tout au moins ne se trouvent plus dans la phase aqueuse après la filtration habituelle sur 0,45 mM. Un développement bactérien important sur les particules sédimentaires est certainement responsable de cette consomation d'azote. 
Les fortes concentrations en azote orgarique peuvent expliquer l'inbiticn initiale; la minéralisation progressive pourrait favoriser I'eutrophisation - l'autoclavage réalisé lors de la première phase est un premier pas - bien limité - vers celle-ci, qui est plus importante en milieu réducteur (d'environ 10 \&), le milieu rédiit étant toujours plus riche en azote et phosphore donc conduisant à une production algale plus grande.

\section{2-2 Effets comparés des diffërents sêdiments}

L'action inhibitrice des sêdiments vis-à-vis de la croissance de Selenastrum capricormutum n'est doric pas facilement levée, que ce soit par des lessivages successifs du sêdiment, une filtration plus fine de l'eau d'extraction ou par I'autoclavage préalable du sédiment.

Nous suivrons ici le protocole d'extraction tel qu'il a êté défini initialement (cf. Matériel et Mêthodes). La fixation des conditions : (1) de lessivage (pratiqué une seule fois), (2) de filtration $(0,45 \mathrm{\mu m}$ ), (3) d'autoclavage (non pratiqué), nous permet de comparer les pouvoirs inhibiteurs et fertilisants des fonds mtubles de la Seine.

Les eaux du lessivage des 14 échantilions de sédiments contiennent. à la fois des produits inhibiteurs et eutrophisants. Cette double influence se présente pour chaque station (fig. 6).

Avec l'augmentation des concentraticns, on observe, selon les localitẽs, une inhibition (Montereau, Ile des Cygnes, Poissy) ou une eutrophisation (Flins 1). Généralement les concentrations faibles sont eutrophisantes (maximum d'eutrophisation pour 25 et 50 \& de 1 'extrait. Par contre, pour les fortes concentrations et dans le cas de l'extrait pur, 1 'eutrophisation est moindre, ou une inhibition apparait : c'est le cas de la plupart des échantillons. La séquence suivante se présente donc habitueliement en fonction des concentrations : eutrophisation puis progressivement inhibition.

Quels sont les agents responsables de ces effets ?

L'azote et le phosphore ne peuvent être limitants puisque tous les essais sont réalisés avec une concentration en nutriments au moins égale à celle du milieu de culture pAAP employé comme témoin ( $\mathrm{N}: 300 \mu \mathrm{M} . \mathrm{L}^{-1}$; $\left.P: 6,2 \mu \mathrm{M} . \mathrm{L}^{-1}\right)$. Ces doses sont systématiquement ajoutées aux extraits et à leurs diluticns déjà riches en ces deux élếments (tableau 1).

La non - toxicité apparente de $\mathrm{NH}_{4}$ (jusqu'ä des conceritrations de $140 \mathrm{mg} \cdot \mathrm{L}^{-1}$ ) peut $\mathrm{s}^{\prime}$ expliquer par $2^{\prime}$ oxydation en $\mathrm{NO}_{3}$ durantles 4 jours du test (tableau 5).

Par ailleurs une partie du phosphore est susceptible d'être adsorbée sur les particules donc non biodisponible; néanmoins les tereurs des extraits et de leurs dilutions en substances nutritives sont généralement suffisantes pour assurer le développement des algues. En outre, comme nous l'indiquons plus haut, les plus fortes inhibitions se présentent pour les concentrations maximales c'est-à-dire lorsque les nutriments, mais aussi les substances altéraçènes, sont. le plus abondants. 
Tableau 5.- Nutriments (mg. $\mathrm{L}^{-1}$ ) et métaux lourds $\left(\mu \mathrm{g} \cdot \mathrm{L}^{-1}\right)$ des extraits aqueux réalisés à partir des sédiments de la seine.

Table 5.- Nutrients $\left(\mathrm{mg} / \mathrm{L}^{-1}\right)$ and heavy metals $\left(\mu \mathrm{g} / \mathrm{L}^{-1}\right)$ in water extracts taken from sediments in the River Seine.

\begin{tabular}{|c|c|c|c|c|c|c|c|c|c|c|c|}
\hline & $\mathrm{N} \mathrm{NH}_{4}$ & $\mathrm{~N} \cdot \mathrm{NO}_{3}$ & N. ORG. & P. $\mathrm{PO}_{4}$ & $\mathrm{~Pb}$ & $\mathrm{Cu}$ & $\mathrm{Cr}$ & $\mathrm{cd}$ & $\mathrm{Ni}$ & $\mathrm{zn}$ & $\mathrm{pH}$ \\
\hline BALLOY & 0,7 & 0,21 & 8 & 0,19 & 5 & 80 & 4 & 1 & 80 & 80 & 8,25 \\
\hline MONTEREAU & 28 & 0,12 & 12 & 0,16 & 48 & - & 48 & 2 & 140 & 300 & 7,16 \\
\hline PONTHIERRY & 5,1 & $0,2 \mathrm{i}$ & 26 & 2,1 & 70 & - & 67 & 1 & 53 & - & 7,70 \\
\hline ABLON & 57 & 0,19 & 57 & 2,6 & 58 & 100 & 10 & 1 & 200 & - & 7,84 \\
\hline ILE DES CYGNES & 26 & 0,12 & 24 & 0,28 & 27 & 40 & 47 & 2 & 120 & 400 & 7,56 \\
\hline ACHERES 1 & 28 & 0,14 & 5 & 1,35 & 56 & 60 & 153 & 9 & 120 & 300 & 7,74 \\
\hline ACHERES 2 & 95 & 0,28 & 0 & 4,32 & 43 & 20 & 42 & 2 & 280 & 300 & 7,47 \\
\hline ACHERES 3 & 46 & 2 & 18,5 & 4,8 & 29 & 40 & 57 & 3 & 40 & 400 & 7,40 \\
\hline ACHERES 4 & 40 & 0,2 & 43 & 2,8 & 24 & 40 & 48 & 1 & 100 & 300 & 7,14 \\
\hline TALBOT AMONT & 140 & - & - & 5,8 & 10 & 32 & 35 & 3 & 140 & 300 & - \\
\hline TALBOT AVAL & 65 & - & - & 1,7 & 56 & 59 & 50 & 2 & - & - & - \\
\hline POISSY & 50 & 0,3 & - & 2,4 & - & - & - & - & - & - & 7,60 \\
\hline FLINS AMONT & 13,5 & - & - & 2,5 & 20 & 15 & 27 & 1 & 140 & 400 & - \\
\hline FLINS AVAL & 50 & - & - & 1,7 & 17 & 26 & 61 & 3 & 280 & 300 & - \\
\hline
\end{tabular}




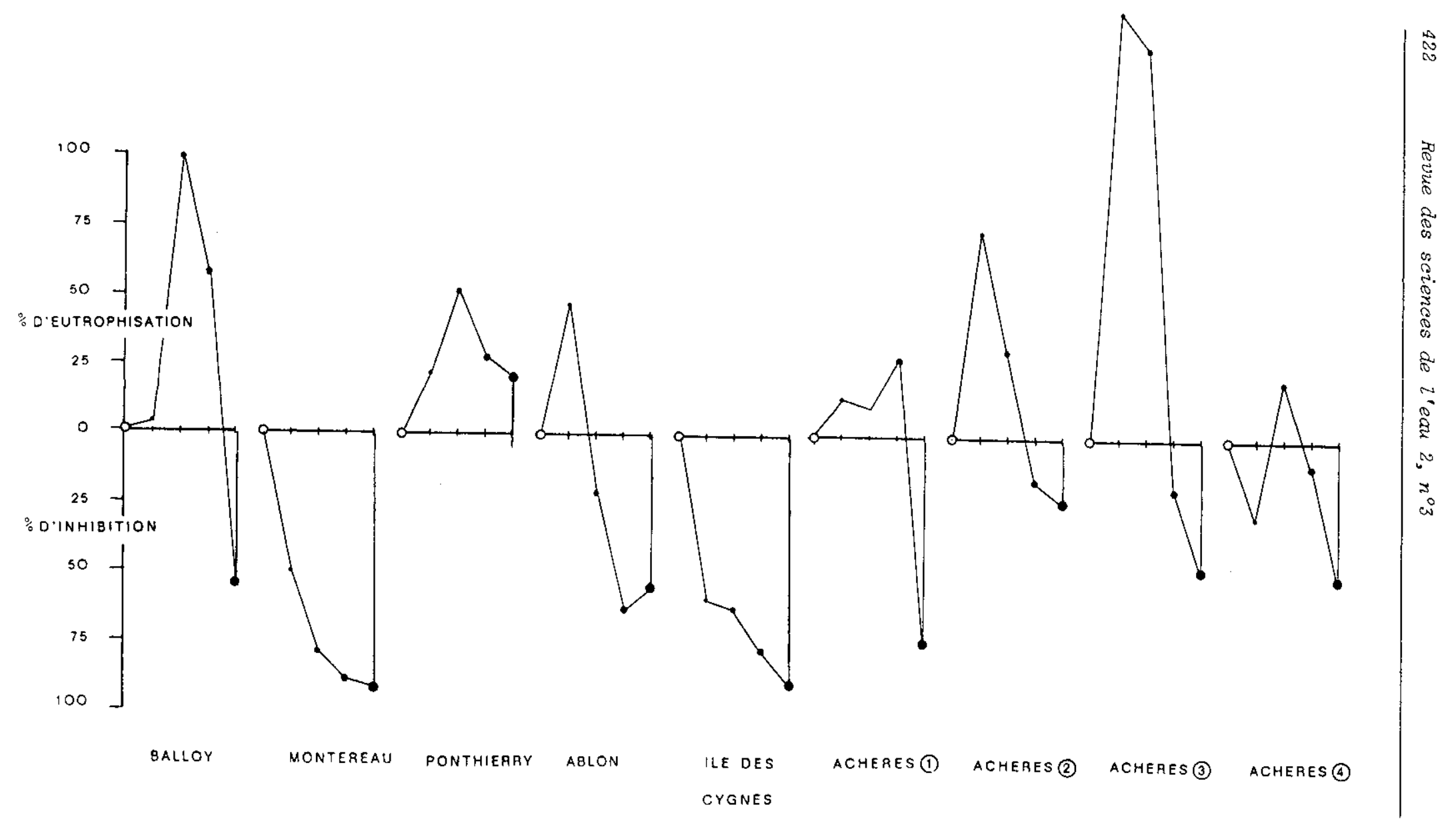



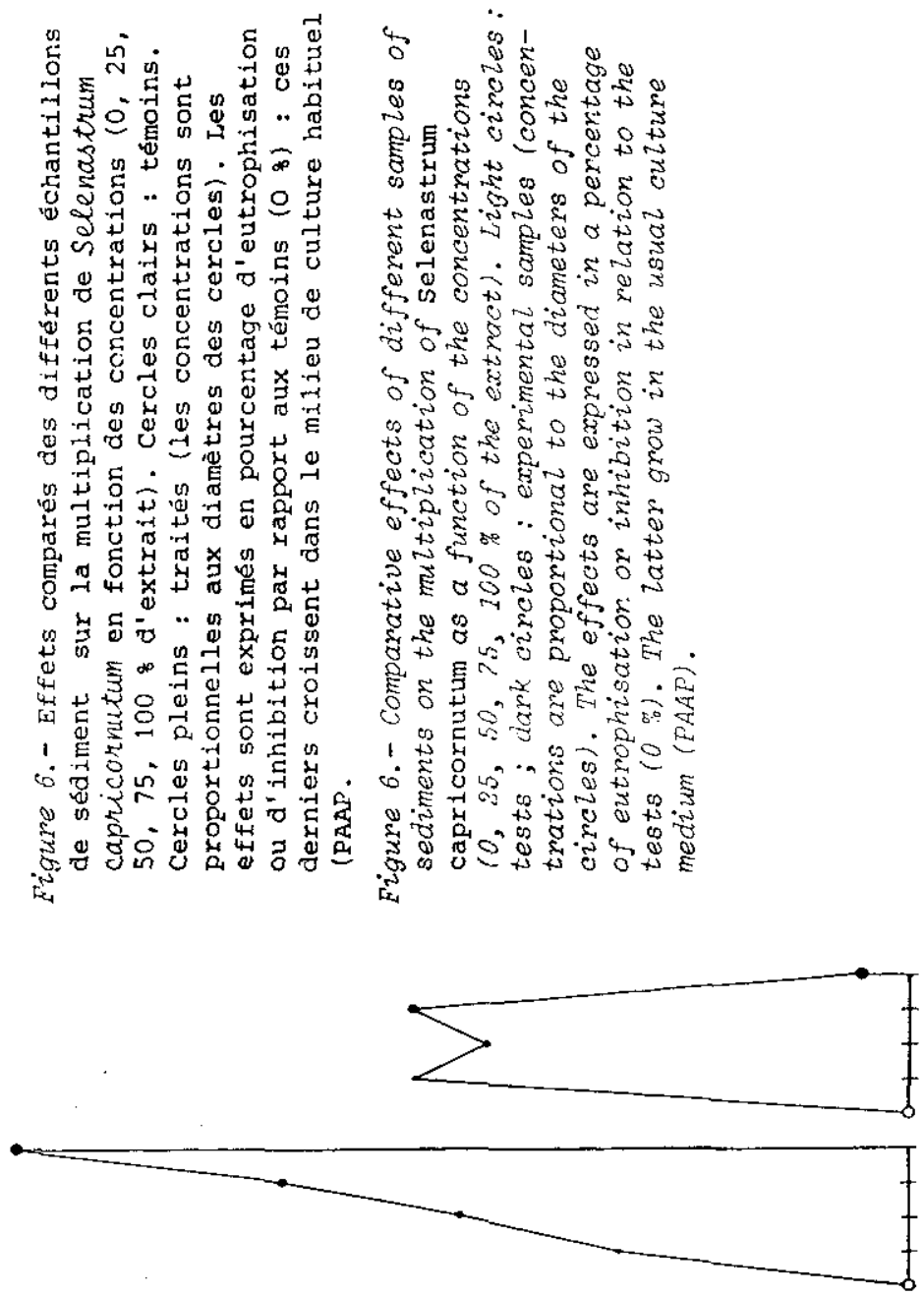

$\Theta_{0}$
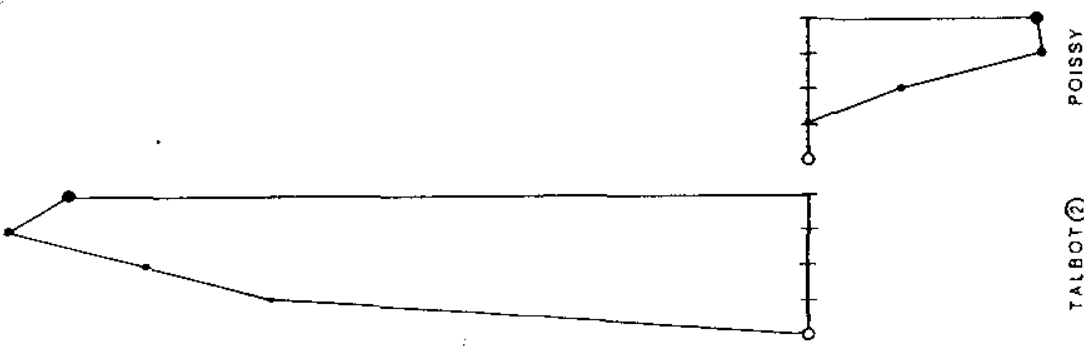

0
5
0
0
4
5

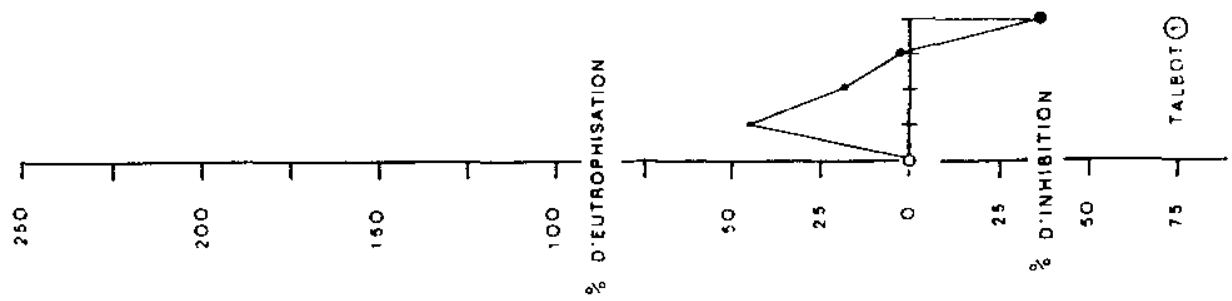


Il ne semble pas, en regard de la figure 6 et du tableau 5, que 1'on puisse clairement attribuer les inhibitions corstatées aux métaux. Ceuxci sont dosés sur les échantillons d'eau avant dilutior. D'autres substances sont donc en cause. Ci-dessous les concentrations maximales en métaux lourds :

$\begin{array}{llr}\mathrm{Pb} & \text { jusqu'à } & 70 \mu \mathrm{\mu} \cdot \mathrm{L}^{-1} \\ \mathrm{Cu} & \text { jusqu'à } & 100 \mu \mathrm{\mu} \cdot \mathrm{L}^{-1} \\ \mathrm{Cr} & \text { jusqu'à } & 150 \mu \mathrm{\mu g} \cdot \mathrm{L}^{-1} \\ \mathrm{Cd} & \text { jusqu'à } & 9 \mathrm{\mu g} \cdot \mathrm{L}^{-1} \\ \mathrm{Ni} & \text { jusqu'à } & 280 \mu \mathrm{\mu} \cdot \mathrm{L}^{-1} \\ \mathrm{Zn} & \text { jusqu'à } & 400 \mu \mathrm{\mu} \cdot \mathrm{L}^{-1}\end{array}$

Pourtant, CHIAUdANI et VIGHI (1978) au cours d'expériences réalisées avec la même algue indiquent des toxicités plus importantes. Or ces auteurs utilisent le même chélateur (EDTA) à la même concentratior. (300 $\left.\mathrm{\mu g} \cdot \mathrm{L}^{-1}\right)$. Rappelons que ce produit est introduit ici avec les microéléments métalliques en début d'expérience pour toutes les eaux étudiées (tableau 1).

Nous noterons cependant que les expéxiences de CHIAUDANI et VIGHI (1978) sont conduites avec le milieu de culture habituel (tableau 1) ; or, celui-ci est sans rapport au plan physico-chimique avec les milieux complexes constitués par les extraits de sédiments. Ces derniers contiennent des composés organiques en quantitês importantes susceptibles d'avoir des propriétés chélatrices supplémentaires affectant l'activité des ions métalliques et par ce biais $d^{\prime a v o i r ~ u n e ~ a c t i o n ~ s u r ~ l e s ~ p r o d u c-~}$ teurs primaires (BARBER et RYTHER, 1969 ; LACAZE et VILLEDON de NAĨDE, 1977). HANNAN et PATOUILLET (1979) à l'occasion de travaux portant sux des sols et des sédiments de l'Etat de Whashington indiguent qu'il $n^{\prime} y$ a pas de coxrélation entre la teneur des sédiments en $\mathrm{Pb}$, Cu et $\mathrm{Zn}$ et le développement des algues. Ils indiquent par ailleirs (1976) que 1 'analyse chimique des extraits de sédiment $n$ 'a que peu d'intérèt : les données les plus fiables correspondent à celles fournies par les bioessais. En bref, d'après ces auteurs (comunication personnelle), le test $n^{\prime}$ est pas très sensible à la pollution des sédiments car les métaux louras leur sont étroitement liếs et ne sont pas aisément relâchés dar:s le milieu ; quelle est alors l'origine des inhibitions décelées par ces bioessais?

Ies fortes concentrations en azote organique observées ici pourraient expliquer certaines des inhibitions observées (actions de complexatior. voire antibiotiques).

Par ailleurs, à l'aide d'expériences rểalisées avec des milieux dans lesquels différentes concentrations de matières organiques d'origine aquatique sont dissoutes dans un substrat synthétique (PAAP) ainsi qu'en utilisant de l'eau naturelle, VISSIER et COUTURE (1981) ont démontré que la croissance et le taux de photosynthèse de l'algue Selenastrum coppicornutum sont influencés par les propriêtés de la matière organj.que et que celles-ci varient au cours des saisons. Il apparaft, d'après ces auteurs, que la matière organique servirait comme source d'éléments nutritifs aussi bien que comme agent stimulateur ou inhibiteur de processus physiologiques. Les fractions à poids moléculaires faibles seraient physiologiquement plus actives que celles à poids moléculaires plus élevés.

D'autres substances peuvent agir sur la production d'al.gues. CROUZET et VILLESSOT (1987) signalent que le développenent des algues est. 
d'autant plus important que les eaux sont plus minéralisées. "Il est évident que le calcium, le magnésium et l'alcalinité des eaux naturelles sont essentiels à la formation de la biomasse", néanmoins dans le cas des eaux de lessivage étudiées ici, les teneurs en Ca et Mg ne semblent pas être excessives puisque du même ordre que celles que l'on rencontre habituellement dans les eaux de la seine et par conséquent avoir d'influence (tableau 6).

Tableau 6.- Degré de minéralisaticn des eaux d'extraction du sol de référence et de 6 types de sédiments (mg. $L^{-1}$ ). Table 6.- Degree of mineralization of extraction watere from the reference soil and from six types of sediment $\left(m g / L^{-1}\right)$.

\begin{tabular}{lccc}
\hline & $\mathrm{Ca}$ & $\mathrm{Mg}$ & $\mathrm{SO}_{4}$ \\
\hline Sol & 31,6 & 2 & 60 \\
Balloy 1 & 34,1 & 3,2 & 17 \\
Balloy 2 & 20,8 & 6,6 & 35 \\
Donthierry & 35,8 & 5 & 20 \\
Ablon & 63,3 & 6,6 & 23 \\
Achères 4 & 133,3 & 18 & 40 \\
Poissy & 39,1 & 6,5 & - \\
\hline
\end{tabular}

\section{CONCLUSION}

Comment, à partir d'un sédiment, obtenir une image réaliste, au plan écologique de son caractère inhibiteur ou fertilisant ? Bien que l'étude "in toto" du sédiment ne doit pas être écartée (IAACAzE et al., 1989), une extraction est généralement nécessaire. L'état physico-chimique et par conséquent toxicologique de la phase aqueuse extraite du sédiment dépendra des conditions de 1'extraction. Au cours de cette étude exploratoire nous avons considéré certaines d'entre elles : ainsi, nous constatons que $1^{\prime}$ action inhibitrice du sédiment vis-à-vis de la croissance à couxt terme de la micro-algue Selenastrum capricomutum n'est pas aisément levée, que ce soit par des lessivaģes successifs du sédiment, par une filtration plus fine de l'eau extraite à partir de ce dernier ou par un autoclavage préalable de ce mếme sédiment.

En fonction des réstiltats précédents nous avons détexminé un protocole provisoire d'extraction poir comparer entre eux les pouvoirs inhibiteurs des sédiments provenant de plusieurs localités dì lit de la seine.

Cette etude nous permet de mettre rapidement en évidence les sédiments les plus inhibiteurs de la seine (rếgion parisienne), c'est le cas notamment des échantillons provenant de Poissy, Montereau, Ile des 
Cygnes, Ablon qui sont inhibiteurs même pour les plus fajbles concentrations. Quelle est l'incidence de ces effets sur les chasnes trophiques ? y a-t-il une relation entre ces résultats et les altérations de la faune pisciccle que nous observons depuis quelques années dans certaines localités telle que Montereau ? Notons que la pollution d'origine humaine n'est pas toujours en cause puisque des stations non polluées à ce point de vue (Balloy 2) présentent également une forte inhibition (fig. 5).

Une constatation déjà faj.te par HANNAN et RATOUILLET (1976) est ici confirmée : il n'y a pas corrélation entre la teneur en métaux louras des eaux du lessivage des sédiments et le développement des algues. Sur un plan plus général on peut affirmer que l'analyse chimique, jamais exhaustive, ne rend pas toujours compte de l'effet réel de la pollution des sédiments : $I^{\prime u t i l i s a t i o n ~ d e ~ t e s t s ~ e s t ~ d o n c ~ u n e ~ n e ́ c e s s i t e ́ ~ c o m m e ~}$ l'ont souligné les auteurs précitếs et LACAZE (1987).

Dans le cas de $l$ 'organisme de référence Selenastrum capricomutum, ces travaux nous indiquent donc que l'eutrcphisation de la seine, à laquelle participent. les sédiments, puisque riches en nutriments, n'est pas fxeinée par la présence de métaux lourds. Si ces derniers ne sont pas directement en cause il convient de dêterminer l'origine des inhibitions observées. Ia matière orgarique, qui par ailleurs a une influence comme source d'éléments nutritifs et comms agent stimulateur, agit probablement ici par ses propriêtés antibiotiques ou de complexation.

\section{RÉFÉRENCES BIBLIOGRAPHIQUES}

AFNOR (1980). Détermination de l'inhibition de croissarce de Scenedesmus subspicatum par une substance. Norme experimentale T 90-304, 6 p..

BARBER R.T., RYTHER I.H. (1969). Organlc chelators Eactor affecting primary production in the crowwell current upwelling. J. exp. mar. Biol. Ecol.; 3: 191-199.

BLANDIN P. (1986). Bioessais et bioévaluation, 233-243, In : Bioindicateurs et diagnostic des systèmes écologiq̨ues. Bull. Eool., 17, 4.

BLANKLEY W.F. (1973). Toxic and inhibitory materials associated with clilturing, 207 229. Handbook of Phycological

methods : Cambridge University Press.

BONIN D.J., DROOP M.R., MAESTRINI S.Y., CONIN M.C. (1986). Physiological features of six micro-algae to be used as indicators of sea water quality. Cyptogamie, Algologie, 7 (1): 23-83.

CHIAUDANI G. . VIGaI M. (1978). The use of Selenastrum capricornutum batch cultures in toxicity studies. Mitt. Int. Ver.

Limol., 21: 316-329.
CROUZET F., VILLESSOT D. (1987) . Biodisponibilité du phosphore. Aspects crimiques, biochimiques et enviromementaux 107-135, In : Poirit sur 2'spuration et le traitement des effluents. Volune 3. Technique et Documentation, Lavoisier, Paris.

EPA (1978). The Selenastrum capricornutum algae assay bottle test. National eutrophication research program. EPA Paciflc northwest laboratory, Corvallis, Oregon.

HANNAN P.J., PATOUIULT C. (1976). LACK of Correlation between the composition of sediments and their toxicity to algal N.R.L. Report 8019, Washington DC, 18 P..

HANNAN P.J., PATOUILLET C.E. (1979). Results of an algal toxicity test applied to sediment elutriates. N.R.L. Report 3952, washington DC, 24 p..

IACAZE J.C. (1973). Influence de 1'éclairement sur la biodegradation d'un tensioactif non ionique utilisé pour la dispersion des nappes de pétrole en mer. $C . R$. Acad. Sci., Paris, 277: 409-412. 
LACAZE J.C. (1976) . Expériences de pollution en éccosystemes marins contrólés. Applications aux produits petroliers. Oceanis, 2: 1-115.

LACAZE J.C. (1987). Evaluation du degré de pollution des sédiments marins au moyen d'un test sublétal, l'effet sur $l$ 'activité photosynthétique de 1 'algue planctonique Pharodactylum tricornutum mesurée par assimilation de ${ }^{14} \mathrm{C}$. C.3. Acad. Sci., Paris, 305(III) : 515-520.

LACAZE J.C., VILIEDON DE NAİDE O. (1977). Effect of Organic Excretion by Benthic Annelida on the Productivity of Phytoplancton. Int. Rev. ges. Hyambiol., 62(1) : 153-155.

LACAZE J.C., PAQUET F. (1989). Tests d'evaluation du degré de pollution des sédiments marins : effets sur la production de larves et la consomration d'algues chez le copépode Tigriopus brevicornis. Rev. Sci. Eau, 2(1): 1-12.
LACAZE J.C., BORDALO A.A., CHESTERIKOEF A., OLIIVON D. (1989). Evaluation de 1 'État de santé des sédiments de la Seine (région parisienne) par 1 'emploi d'enceintes dialysantes. Effets sur le taux de croissance et la biomasse maximale de cuitures de la microalgue Selenastrum capricornutum. C.R. Acad. Sc., Paris, 308(III), 49-54

MAESTRINI S,Y., DROOP M.R., BONIN D.J. (1984). Test algae as indicators of sea water quality : prospects In : L.E. Shubert (Ea.), Algae as ecclogica? indisators. Academic Press London, pp. 133-i88.

SCOR-UNESCO (1966). Working group 17. Determination of photosynthetic pigments in sea water. Monogr. Oceanogr. Method. Unesco, (1).

VISSER S.A., COUTURE P. (1981). LeS effets de la matière organique dissoute d'une eau douce sur la croissance de l'alque Selenastrum capricornutum, iaten Res., 15: 1355-1361. 